\title{
Leveraging Social Media in Accommodating Collaborative Learning in Indonesian Islamic Higher Education
}

\author{
Jamridafrizal, Basuki Wibawa, Nurdin Ibrahim
}

\begin{abstract}
The aim of this study is to develop a Social Media-based Online Collaborative Learning (SMOCL) instructional model for higher education that can systematically guide lecturers or teachers to create a suitable blend of individual online lectures and face-to-face collaborative learning activities. Using the ADDIE instructional design model (Analysis, Design, Development, Implementation, and Evaluation), a theoretically constructed beginning model was repeatedly upgraded and undertaken internal validation through expert reviews, while External validation was performed with one-to-one with students, small group, and field trials. The implementation of SMOCL at the Islamic University of Indonesia designed by the final model resulted in notable amounts in student performance, attention, relevance, trust, and satisfaction. The results seem to suggest that the SMOCL model can be served to promote students' achievement in cross-cultural understanding.
\end{abstract}

Keywords: Social Media; Collaborative Learning; ADDIE; Cross-Cultural Understanding

\section{INTRODUCTION}

In recent years, Facebook has become the most popular social networking platform that allows users to share details about their location, share the types and content of news that they have consumed, and share information on recommendations from other trusted users. Facebook status updates can be automatically reposted to other sites, such as Twitter or LinkedIn, or widgets. In addition, users can constantly update their status and share content such as newspaper articles and links to certain sites.

According to The Statistics Portal data, in 2015 Facebook users in Indonesia have reached 70.6 million and it is estimated that in 2018 it will reach 97.5 users. The data shows that at least every year there are 10 million Facebook users in Indonesia, the majority of whom are teenagers, especially students. With its advantages and features, Facebook has become a strength as well as a huge

Revised Manuscript Received on September 22, 2019.

Jamridafrizal, Department of Educational Technology, Postgraduate Program Universitas Negeri Jakarta, Jakarta, 13220, Indonesia. jamridafrizal@uinbanten.ac.id

Basuki Wibawa, Department of Educational Technology, Postgraduate Program Universitas Negeri Jakarta, Jakarta 13220, Indonesia. bwibawa@unj.ac.id

Nurdin Ibrahim, Department of Educational Technology, Postgraduate Program Universitas Negeri Jakarta, Jakarta 13220, Indonesia. nurdin1349@yahoo.com potential that is used by educators in universities to facilitate student learning, because the use of Facebook as a medium in learning can increase academic value (Alhazmi and Rahman, 2012), involving students actively implicated in working on various tasks, sharing contents, communicating and collaborating actively with their peers in groups (Junco, 2014). In addition, Facebook provides multitasking capabilities that enable students to ask questions and solve common problems (Lam, 2015), the teaching and learning process becomes more flexible. Facebook also can foster communication between lecturers and students on an ongoing basis for long periods of time, actively embroiled, involves students vigorously learning because they are stimulated, encouraged and lured into navigating various information sites, posting comments and engaging in online discussions (Ventura and Quero, 2013). In addition, Facebook can significantly enhance group work (Roodt, de Villiers, and Joubert, 2012), providing more opportunities for students to communicate and work together to build their own learning and develop 21st-century skills to live and learn through social interaction (Shraim, 2014).

Based on the results of the preliminary studies that were conducted, most of the lecturers and students in the study program of teaching English in the UIN (State Islamic University) Sultan Maulana Hasanuddin (SMH) Banten Indonesia, already have mobile devices and accounts on Facebook. However, the use of online social networks is still limited to information sharing, ranging from information on lectures, books, files, and other academic information individually and in groups. Even if it is well organized, this condition has the potential for large social networks to facilitate collaboration, among students in lecture activities, for example in giving assignments, discussions and monitoring the activities of students who are discussing. Unfortunately, the internet network that has been available for a long time in the campus environment has not been used optimally for learning purposes that combine face-to-face learning models by online.

As an institution that serves to prepare professional teachers in the future in the field of English language teaching, there are many requirements to become a leading study program by 2020 , including facilities that support technology-based learning. As a candidate for the 21st-century teacher, students should be prepared to become professional teachers who are




able to meet the needs of students of their era. Vicky Zygouris Coe (2014) argues that for students who want to be a success in the world today and tomorrow, they should learn from teachers who have good preparation who also accept lifelong learning, adapt, and create change, and collaboratively solve complex practical problems with colleagues.

Lecturers need to develop a culture of collaborative inquiry and appreciation, pay attention to the diversity of their students, use formative and summative assessments, and promote monitoring of students' self-learning. The role of 21 st-century educators is as a student learning facilitator, similar to an orchestra conductor, lecturers must guide students to access, build, produce, analyze, evaluate, synthesize, create, and disseminate knowledge. Technology is the center of life and the study of students. They have high expectations about how to learn, choose the technology and environment that suits their needs with a sophisticated understanding of how to manipulate this for the benefit of their learning.

\section{Literature REVIEW}

\section{A. Social Media as Learning Tool}

The rapid development of new media and technological tools raises opportunities to improve learning by encouraging the use of these tools to promote learning. Thus, one of the major challenges today is to find out the way to give assistance students to create, navigate, grow the powerful individualized networks of learning, and participate in the Web in safe, ethical, and effective ways. The new literacy means being capable to function in and harness potential of easy-to-create, collaborative, transparent in online communities and networks, which reflect a "tectonic shift" in the way we require to think about the world and our place in it (Shirky, 2008).

Social constructivist theories emphasize the importance of culture and context in understanding what is experienced by the community and in building knowledge, Pritchard, Alan, and Woollard (2013) emphasized on three aspects of social constructivist thinking, namely are reality, knowledge, and learning:

- Reality: Social constructivists convince that reality is built through sharing human social activities.

- Knowledge: Social constructivists assume knowledge is a human creation and its creation is only possible in a social ways

- Learning: Social constructivists views learning as a social process where individuals create meaning and get knowledge when individuals interact with social activities (Alan, and Woollard ,2013).

Many criticisms were directed towards online learning models in various forms, both fully online and blended learning that combine online and face-to-face learning. For them, the online learning model is below standard, lack of interaction between teachers and students, technological difficulties, lack of motivation for students and responsibility for their learning. Nevertheless, online learning has become an established part of the educational landscape. An online environment to support direct learning needed for certain types of learning outcomes

There are many ways to design meaningful online learning that includes active engagement, the interaction between instructors and students, and high-quality learning experiences using a variety of teaching strategies and technology support. According to Dabbagh, Mara, and Howland (2019), meaningful learning can be described as learning that has value, purpose, and significance. Online learning has the potential to be created into meaningful learning if teachers and learning designers are able to overcome the five meaningful learning characteristics. The five characteristics involve:

- Constructive learners: Learners can build knowledge when they learn from each other about interpreting data from each sample.

- Cooperative learners: Learners can collaborate through discussion forums.

- Authentic learners: Learners are involved in discussions about their results will increase authenticity in learning.

- Intentional: Given that discussion activities are directly related to meaningful tasks in which students are involved, and that the results of the discussion can help students in their analysis, the discussion has the potential to be intentional.

- Active learners: Learners can be actively involved in discussions when they share the results and collaborate in interpreting them.

Social media offers advantages and features that have never existed before. The emergence of tools such as blogs, social networks, and blogs has had a prominent impact on higher education when new ways of getting involved became available to instructors. The impact of social networking is no longer debated, and social media is seen by some as revolutionary, set to change the face of higher education. Therefore, it is a challenge for educators today to choose the right social media tools for learning assignments and can develop student skills by combining them into learning and curriculum in meaningful ways so that students can be actively involved in learning.

As a pedagogical tool, the role of social media in higher education involves five dimensions examined by researchers in various disciplines that refer to pedagogical research, social capital theory, information technology, legal studies, and other fields, including (1) functioning as network enabler. (2) marketing and recruitment tools, (3) collaboration, (4) teaching and learning tools, and (5) media that present career management and entrepreneurial opportunities (Vladlena, 2014). While according to Chickering and Gamson (1987, 1991), social media can be used for instructional purposes and can be used to facilitate the following principles: (1) Encouraging contact between students and faculty; (2) Developing mutual relations and cooperation between students;(3) Encouraging active learning; (4) Providing fast feedback;(5) Emphasizing time on assignments; (6)

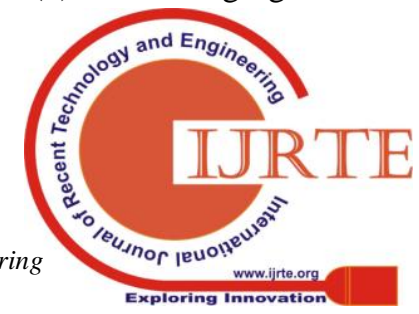


Communicating high expectations. (Taylor, 2015).

\section{B. Social Media as Collaboration Tool}

Vygotsky's sociocultural theory is the main root of collaborative learning which regards learning as vigorously committed naturally through the Proximal Development Zone ( ZPD) (Dennen VP, Hoadley C,2013). The views have essentially donated enormously to social constructivist epistemology and have recognized how learning is mediated according to the context and experience with colleagues (Schunk, D. H., 2015). These notions bridge the causal relationship between social interaction and the development of individual cognitive. Learning, from this approach, is fundamentally facilitated when the students' tasks are expected to achieve potential development through collaboration

Collaborative learning is a form of learning with colleagues in the Vygotsky's views lie in social interplay between students and Lecturers, and among students which facilitate them to develop through ZPD, which refers to the range of difficult tasks for the students to achieve alone except by guidance and assistance from more-skilled peers (Santrock, J.W, 2017). Vygotsky's notions show that actual development refers to already achieving mental-function independently without assistance, on the other hand, the level of potential development refers to mental-function will not be able to function independently when individuals work together with more proficient colleagues, the stage of potential development will increase. In other words, with the help of more skillful peers, individuals are competent to undertake more things maximally and this notion is called potential development

Therefore, the concept of ZPD underlines the linkage between individuals and social processes in co-constructive knowledge in a social environment. Someone has the ability to carry out cognitive tasks independently based on previous social processes because this is considered as the basic principle of socioculturalism where learning lies in a particular context and is influenced by someone's experience in social and cultural activities.

Based on this discussion, collaborative learning naturally facilitate the actual cognitive development level of the students by actively communicating with more capable colleagues. Thus, in ZPD, students are better able to provide colleagues with new notions and thus form interdependent beneficial social learning processes.

As a collaboration tool, potential social media is used to support three key elements of educational achievement, namely, discussion, collaboration, and bringing the experience into spaces. The three elements can be explained as follows:

- Social media supports active learning between students, and students and teachers, and connects students and teachers in various learning activities.

- Social media sites such as Wikis, blogs, Twitter, YouTube, Facebook, Twitter, support both collaboration and cooperation.

- Social media bridges the real world and classrooms. Online tools provide effective ways to connect teachers and students with available resources outside the classroom that cannot be reached in traditional setting. (Natarajan, 2017)

Thus, it is clear that in addition to facilitating students to discuss and share with each other, social media provides space for students to collaborate and to complete classroom assignments, where they can share and communicate with each other. According to Agozzino A (2014) internet interactivity, especially social media collaboration tools allow students to be fully connected with one another.

Through its advantages and features, it becomes a challenge for educators and learning designers to design a learning model that allows students to engage and collaborate actively in online learning environments. According to Reid, Jo-Anne (2002) there are five stages in the collaborative learning model, include engagement, exploration, transformation, presentation, and reflection. Each stage will be described as follows:

- $\quad$ Engagement is described as the time during which students comprise information and engage in an experience that provides their learning basics. Engagement is getting closer to information by reading, thinking, rereading, discussing, writing or recording. Every activity that supports the development of a better understanding of the material or topic.

- Exploration processes provide a general description of what is contained in the information under consideration. This stage can be an open-ended process where students can follow their curiosity to develop engagement by undertaking many forms of tasks.

- Transformation is the stage where the students have involved and have explored, perhaps configured in a form that allows for the presentation to the next stage is transformed into the teacher's angle format and the needs of students, allowing learning objectives to be met. Possible needs must be done with understanding, answering certain questions.

- Presentation is the stage where the students are required to explain what they have learned can play a worthwhile part in the process of moving them from receiving information towards understanding it, and exercising control over it.

- Reflection is an ongoing process that occurs during each of the other stages as well. This stage is aimed to review and revise the idea to make all new ideas become fully understood and assimilated.

The selection of Facebook as a collaborative learning facility and environment for the Cross-Culture Understanding (CCU) subject is also based on the findings of several studies, including Johnny George who examined the use of Facebook for learning English. This study examined the types of English used in the Facebook update status page of the 50 majoring in English in Japan. About three-quarters of them completed a survey about the use of English at the Social Networking Site and small subgroups interviewed. The study shows that students who use Facebook and Twitter increase their use of their second language, even in 
communication with Japanese colleagues. Although these students feel comfortable using a second language on Facebook or Twitter, they generally fail to use the second language in face-to-face communication. Facebook's relationship with English together with the informality of the medium contributes to the desire of students to use their second language (George, 2015). While Kabilan, et.al (2016) in their research suggests that students believe Facebook can be used as an online environment to facilitate learning English. Next is Lintang Patria, Yulianto who researches Facebook features and conducts online learning tutorial simulations using Facebook. The results of this study suggest that way of improving the quality of online tutorials at the Open University by carrying out simulations as follows:

- Identify and group tutorial participants according to the subject taken.

- Share tutorial learning materials in the form of text, files, videos, and other internet resources.

- Evaluate the tutorial by giving short questions, assignments and quizzes

- Providing value for the performance of the tutorial participants.

- Interact with tutorial participants, both asynchronously and synchronously.

The results of the research above show that benefits of online collaborative learning model, among others; (1) learning is more interesting, (2) fostering interest, (3) varying learning methods, (4) using technology in learning (4) facilitating lecturers in delivering material, (5) changing tendency of lecturers to use printed media in traditional setting become developing through online, (6) developing teaching materials met students' needs. These benefits can only be gained if a collaborative learning model is managed properly through suitable models and methods on Social Networking Sites.

\section{METHOD}

This study aims to develop a Social Media-based Online Collaborative Learning Model (SMOCL). To ensure this model is effective, the proposed model is tested through a series of formative evaluations including expert reviews, one-to-one evaluation with learners, small group evaluations, and field trial. The model development procedure was adapted from ADDIE (Branch, 2009)

ADDIE is an acronym for Analyze, Design, Develop, Implement and Evaluate. The ADDIE model provides a simple but systematic approach to the design and development process (Marcus-Quinn and Barbara Geraghty, 2010). This model begins with an analysis of instructional needs and solutions, followed by the design and development of learning objectives and methodologies, implementation of educational content, and summative evaluation of the products produced. Formative and revised evaluations occur through the entire development process to ensure the product complies with instructional objectives (Barbosa and Maldonado, 2011)

This research was preceded by a preliminary study to investigate learning theories that underlie the development of models, instructional design models, and collaborative learning models as a basis for developing learning models of social media-based collaborative learning models.

The first stage of the development of the model, namely the analysis phase in the form of analysis of factors that affect student performance balance on CCU subject subject at in UIN SMH Banten, Indonesia, determine instructional objectives, analyze student characteristics, and assess the adequacy of resources to implement the model learning to be developed.

The design and development phase is a series of activities consisting of task inventory, writing instructional objectives, and writing test instruments. The development of a collaborative learning model refers to the Reid model which consists of steps: engagement, exploration, transformation, presentation, and reflection. (Reid, Jo-Anne,2002)

The implementation and evaluation phase consisted of a series of model effectiveness tests consisting of expert reviews, one-to-one trials with learners, small group evaluation and field trial. The expert review involves 5 SMEs, one-on-one trials with students involving 3 students, a small group test involving 10 students, and a large group test involving 30 students. Tests on students were conducted on students taking CCU subject at in UIN SMH Banten, Indonesia. The evaluation instrument was adapted from Dick, Carey, and Carey (2015) which included 10 criteria, including learning clarity, impact on students, feasibility, goal-oriented, technical, attention, relevance, confidence, satisfaction, and language. Stages of SMOCL development can be seen in figure 1 .
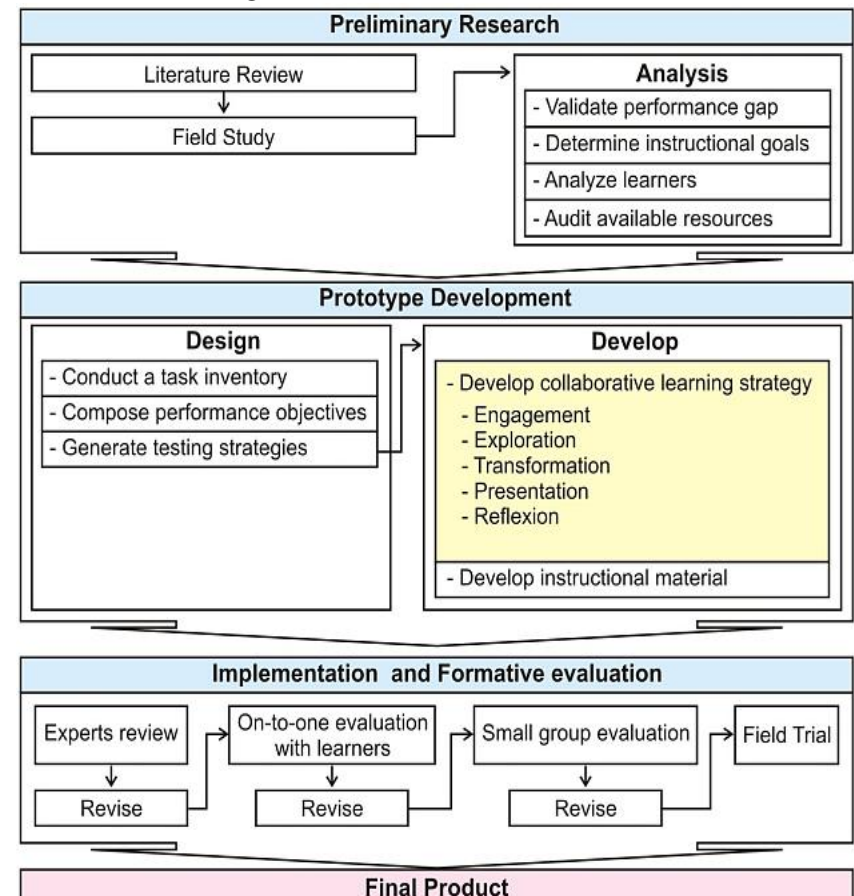

Fig 1. Procedural model of SMOCL development 


\section{FINDING AND DISCUSSION}

The results of the performance gap analysis show that there are student performance discrepancies in the CCU subject caused by overcrowded learning materials, inadequate time allocations, and ineffective teaching strategies.

Based on the results of the analysis of the characteristics of students, all students stated that they have mobile devices to connect with their social media accounts to stay updated with their latest activities, to search for information to complete lectures, watch videos, and chat via a wireless campus network.

Based on the processing of data from the analysis phase, it is concluded that a learning model is needed that allows students to be actively involved and collaborate through social media to overcome the gap in student performance in the CCU subject. The results of task analysis at the design stage are written into instructional objectives to be developed into collaborative learning strategies through Facebook media. The learning strategy developed refers to Reid's collaborative learning model which consists of steps in engagement, exploration, transformation, presentation, and reflection. The stages of setting settings can be seen in figure 2
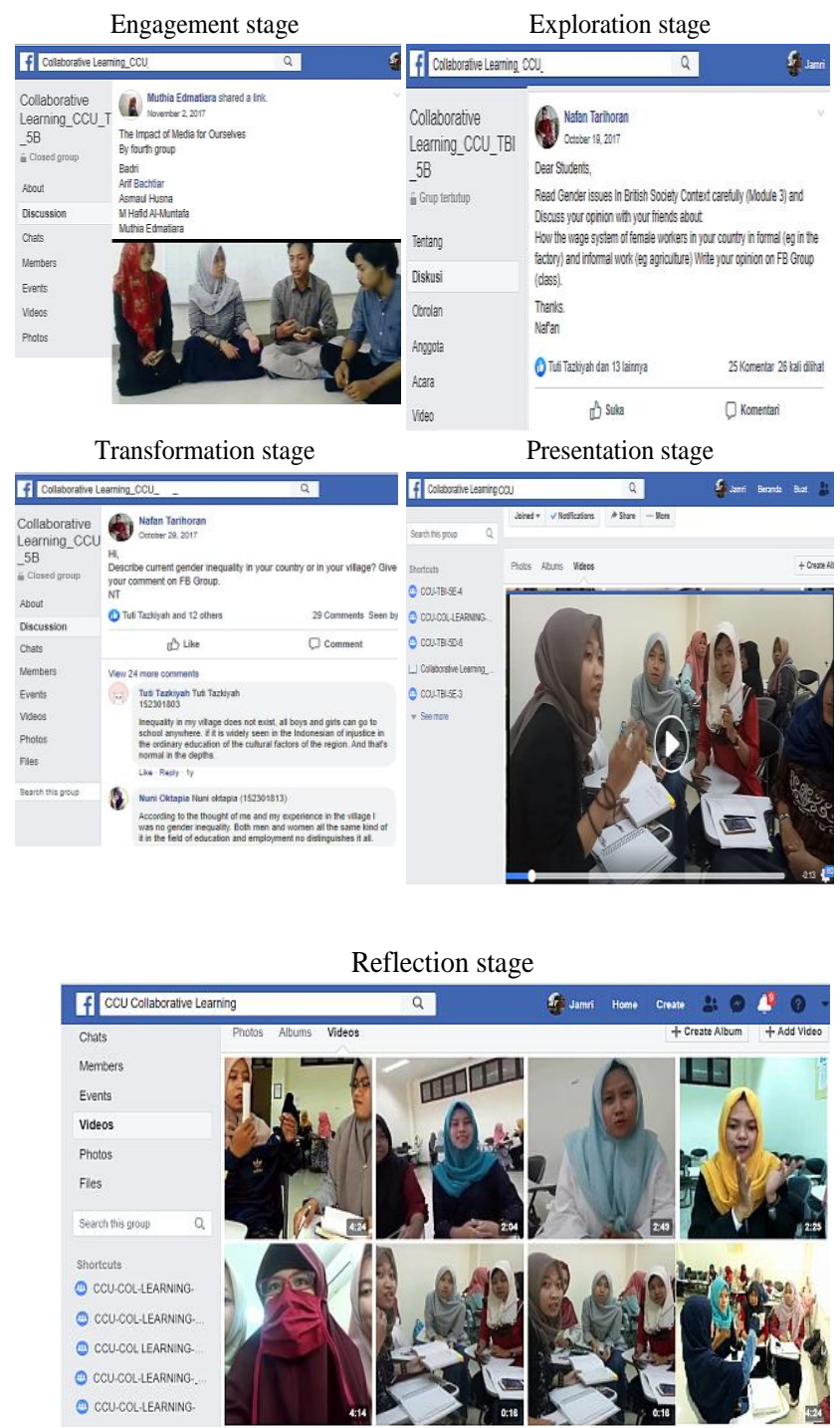

Fig 2. Facebook settings fot SMOCL
After the first draft of the learning model was developed, product prototypes from the results of this study were then tested in a series of formative evaluations to obtain input from experts and learners to revise the learning model developed. The experts involved consisted of instructional design experts, printed media specialists, multimedia specialists, material experts, and linguists. The results of expert, student and peer assessment for learning materials and media at the formative evaluation stage through the data collected through the checklist sheet are as seen in the table 1 .

Table 1. Results of Formative Evaluation

\begin{tabular}{|c|c|c|c|}
\hline Phase & Evaluator & Dimension & $\begin{array}{l}\text { Evaluation } \\
\text { Results }(\widetilde{X})\end{array}$ \\
\hline \multirow{11}{*}{$\begin{array}{l}\text { Expert } \\
\text { Review }\end{array}$} & \multirow{4}{*}{ SME } & $\begin{array}{l}\text { Clarity of } \\
\text { Instruction }\end{array}$ & 4,24 \\
\hline & & $\begin{array}{l}\text { Impact on } \\
\text { learner }\end{array}$ & 4,18 \\
\hline & & Feasibility & 4,20 \\
\hline & & Goal-centered & 4,24 \\
\hline & \multirow{3}{*}{$\begin{array}{l}\text { Instructional } \\
\text { Design Expert }\end{array}$} & $\begin{array}{l}\text { Clarity of } \\
\text { Instruction }\end{array}$ & 4,16 \\
\hline & & Feasibility & 3,92 \\
\hline & & Goal-centered & 4,12 \\
\hline & $\begin{array}{l}\text { Printed Media } \\
\text { Specialist }\end{array}$ & Technical & 3,76 \\
\hline & $\begin{array}{l}\text { Multimedia } \\
\text { Specialist }\end{array}$ & Technical & 3,98 \\
\hline & Linguist & $\begin{array}{l}\text { Clarity of } \\
\text { Instruction }\end{array}$ & 4,08 \\
\hline & & Language & 3,86 \\
\hline \multirow{3}{*}{$\begin{array}{l}\text { One-to-one } \\
\text { with Student }\end{array}$} & \multirow{4}{*}{ Students } & $\begin{array}{l}\text { Clarity of } \\
\text { Instruction }\end{array}$ & 4,02 \\
\hline & & $\begin{array}{l}\text { Impact on } \\
\text { learner }\end{array}$ & 4,28 \\
\hline & & Feasibility & 4,22 \\
\hline \multirow{8}{*}{ Small Group } & & Atttention & 4,16 \\
\hline & \multirow{3}{*}{ Students } & Relevance & 4,06 \\
\hline & & Confidence & 4,09 \\
\hline & & Satisfaction & 3,58 \\
\hline & \multirow{4}{*}{$\begin{array}{l}\text { Peer Team } \\
\text { Teaching }\end{array}$} & Atttention & 4,02 \\
\hline & & Relevance & 4,12 \\
\hline & & Confidence & 3,85 \\
\hline & & Satisfaction & 4,12 \\
\hline \multirow{8}{*}{ Field Trial } & \multirow{4}{*}{ Students } & Atttention & 4,26 \\
\hline & & Relevance & 4,18 \\
\hline & & Confidence & 4,18 \\
\hline & & Satisfaction & 4,14 \\
\hline & \multirow{4}{*}{$\begin{array}{l}\text { Peer Team } \\
\text { Teaching }\end{array}$} & Atttention & 4,12 \\
\hline & & Relevance & 4,17 \\
\hline & & Confidence & 4,02 \\
\hline & & Satisfaction & 4,14 \\
\hline
\end{tabular}

In the next step, the effectiveness of the developed model was tested through the pretest and posttest of student learning outcomes in the field trial which was the last step in formative evaluation.

Published By: Blue Eyes Intelligence Engineering \& Sciences Publication 
Respondents consisted of 30 students who took CCU subject at the UIN SMH Banten Indonesia. The results of the paired t-test with SPSS statistical tests showed a significant increase in student learning outcomes at a confidence level of $95 \%$, with a t-test value of -24.772 smaller than $\mathrm{t}$-table $-2.045(\mathrm{n}=30)$. Thus it can be concluded that the social networking-based collaborative learning model has a significant effect on student learning outcomes. In addition the table above shows that there is an increase in the value of student pretest-posttest and there is a significant correlation with a correlation value of 0.696 and a significance value of 0,000 smaller than 0.005 , so it can be concluded that a social-based online collaborative learning model is developed to improve student learning outcomes for the CCU subject at UIN SMH Banten, Indonesia.

Quantitative data obtained through questionnaires used to determine the level of attention, relevance, confidence and student satisfaction with the developed model are shown in the figure 3 .



Fig 3. Students and peer team teacher level of attention, relevance, confidence, and student satisfaction with the SMOCL

The graph above shows that the average level of attention according to students and lecturers is 4.19 from a scale of 5 , the level, the level of relevance is 4.175 , the level of trust is 4.10 , and the level of satisfaction is 4.14 . This means that the collaborative learning model can raise lecturers and student's attention, the relevance of the learning material, self-confidence, and satisfaction.

The study of collaborative learning has become part of the learning sciences from the beginning. However, many articles use different definitions of understanding collaboration. Each author gives different reasons and methods. The concept of collaborative learning is initially carried out in the classroom. Where lecturers and students physically present at the same place and time. Along with the development of information and communication technology in everyday life, the instructors also use it for the benefit of learning. In collaborative learning everyone in the class participates, works as a partner or in a small group. Questions, problems, or challenges create something that invigorates group activities so learning activities unfold in a general way. Collaborative learning can provide opportunities to go towards improving learning practices in higher education.

According to Panitz in Stacey (2004), discussing on the internet is also called collaboration. Collaboration is an

interaction philosophy and a personal lifestyle is not only a technique in the class where collaboration is also an interaction structure designed to facilitate the fulfillment of the final product or goal. Students in educational, professional and social contexts are no longer just recipients of information; collaborative education technology allows them to act, react, and interact superior new forms of knowledge which in turn are shared and made available to others.

Collaborating through social networking sites is a phenomenon that cannot be avoided and must be utilized. I-Tsun, et.all (2011) showed that Web 2.0 social networking is feasible as a tool by which students to motivate their colleagues to collaborate and learn to complete tasks and overcome challenges. Research of Maqableh, et al. (2015) showed that there was a significant effect of social networking sites on student academic performance. Besides that, there is also a significant effect of using social networking sites per week on student academic performance. This finding can be used to suggest future strategies in increasing student awareness in efficient time management and better multitasking which can lead to increased learning activities and academic achievement.

Students now live in a technology-mediated world. The media shapes how students learn and how they know especially in the present and beyond. Social media provides users with dynamic ways to interact with each other to evaluate knowledge, create and share, which encourages interaction and participation. In addition, students and teachers have got two main benefits on Facebook, namely:

- Facebook allows group members to share information and ideas easily and serves as a platform to communicate easily among group members.

- Facebook enables various types of collaboration in a conducive environment and also allows teachers to trace the progress of the contributions by group members (Wong et .al, 2012)

In addition to the reasons above some research results indicate that Facebook's strengths as a collaborative learning tool, among others: Facebook promotes collaborative work (Laura A Wankel and Patrick Blessinger, 2011), supports active learning (Junco, 2014), involves students in learning (Couillard in Patrut and Bogdan, 2013), encourages group collaboration. Roodt, Villiers, and Joubert (2012), drives positive attitudes of students to study (Shraim, 2014), facilitates multitasking (Lee, 2015), enhances flexibility (Ventura and Quero, 2013), and increase the familiarity and intensity of communication between educators and students and save costs (Hurt, et al.,2012)

The results of this study indicate that the use of Facebook in an online collaborative learning model is effectively used as a medium in learning. Besides having Facebook, it has various features that can function as a media that supports collaboration. characters owned by Facebook can fulfill the role of media as a content channel, as a language, and as an environment. 
This study has a close similarity with a study conducted by Zurweni, Wibawa, and Erwin (2017) that developed a collaborative-creative learning model using virtual laboratory media for instrumental analytical chemistry lectures. The study concluded that the learning model was effective to use for Instrumental Analytical Chemistry lectures. Another study conducted by Wibawa and Kardipah (2018) that developed the Flipped-Blended Model for STEM Education to Improve Students' Performances. The study concluded that the model can improve students' performance in STEM education.

\section{Conclusion}

The findings of this study indicate that (1) Social Media-based Online Collaborative Learning (SMOCL) improves student learning outcomes. SMOCL can facilitate students and lecturers actively involved in working on various tasks, sharing content, communicating and collaborating vigorously with their classmates in groups in a blended environment. (2) SMOCL increases the level of attention of students and lecturers in learning. The use of technology and social media that fits their learning needs can increase their interest and enthusiasm for learning. (3) SMOCL is relevant to facilitate CCU subject matter. Learning material based on the instructional analysis in accordance with the objectives of CCU subject (4) SMOCL increases the confidence of students and lecturers. Facebook's ability to provide a place to discuss and collaborate to increase the confidence of students and lecturers to be actively involved in completing learning tasks (5) Students and lecturers are satisfied with implementing SMOCL in learning. Students and lecturers are able to interact more to improve learning CCU subject better.

Based on the findings of this study, SMOCL can be implemented for CCU subject at the UIN SMH Banten, Indonesia.

\section{ACKNOWLEDGEMENT}

We would like to acknowledge: Department of Educational Technology of Postgraduate Programme, State University of Jakarta, Prof. Dr. Basuki Wibawa, Prof. Nurdin Ibrahim for their support as a promoter.

\section{REFERENCES}

[1] Agozzino A. Building and maintaining relationships through social media. In Building Online Communities in Higher Education Institutions: Creating Collaborative Experience. Hershey, PA:IGI Global;IGI Global.2014

[2] Alhazmi AK, Rahman AA. Facebook in Higher Education: Social and Academic Purposes. International Journal of Computers \& Technology. 2013;12(3):3300-5.

[3] Barbosa EF, Maldonado JC. Collaborative development of educational modules: a need for lifelong learning. E-infrastructures and technologies for lifelong learning: next generation environments. Hershey, PA: IGI Global; 2011.

[4] Branch RM. Instructional design: The ADDIE approach. New York:Springer; 2009.

[5] Dick W, Carey L, Carey J. Introduction to instructional design. The systematic design of instruction. Boston, MA: Pearson; 2015:2-15.

[6] George J. Facebook to Facebook Encounters in Japan: How an Online Social Network Promotes Autonomous L2 Production. New Media and Perennial Problems in Foreign Language Learning and Teaching. Heidelberg: Springer; 2015.
[7] Dennen VP, Hoadley C. Designing collaborative learning through computer support. The international handbook of collaborative learning. New York: Routledge, 2013

[8] Junco R. Engaging students through social media: Evidence-based practices for use in student affairs. San Francisco, CA: Jossey-Bass; 2014.

[9] Kabilan MK, Zahar TZME. Enhancing students' vocabulary knowledge using the Facebook environment. Indonesian Journal of Applied Linguistics. 2016;5(2):217-30.

[10] Kardipah S, Wibawa B. How to Improve Students' Computer Skills? A Flipped-Blended Instructional Model for Economics' Students in Higher Education. The Journal of Social Sciences Research. 2018:91-7: 2

[11] Lam J. Collaborative learning using social media tools in a blended learning course, In International Conference on Hybrid Learning and Continuing Education. Wuhan; Springer; 2015

[12] Lee EB. Too much information: heavy smartphone and Facebook utilization by African American young adults. Journal of Black Studies. 2015;46(1):44-61

[13] Maqableh M, Rajab L, Quteshat W, Masa'deh ReM, Khatib T, Karajeh H. The impact of social media networks websites usage on students' academic performance. 2015; 7, (4):159-171.

[14] Marcus-Quinn A, Geraghty B. Design and Development of a Reusable Digital Learning Resource: A Case Study Teaching Japanese Script. Critical Design and Effective Tools for E-Learning in Higher Education: Theory into Practice. Hershey, PA: IGI Global; 2010.

[15] Dabbagh N, Marra RM, Howland J. Meaningful Online Learning: Integrating Strategies, Activities, and Learning Technologies for Effective Designs. New York: Routledge; 2019.

[16] Natarajan M. Exploring Knowledge Sharing over Social Media. Harnessing Social Media as a Knowledge Management Tool. Hershey, PA: IGI Global; 2017.

[17] Patrut M, Patrut B. Editor. Social media in higher education: Teaching in Web 2.0. Hershey, PA: IGI Global; 2013.

[18] Pritchard A, Woollard J. Psychology for the classroom: Constructivism and social learning. London: Routledge; 2013.

[19] Reid, J. Managing small-group Learning. Marrickville Metro, South Wales Australia: Primary English Teaching Association, 2002

[20] Roodt S, de Villiers C, Joubert P. Collaborative learning for the next generation: Using social networks in an undergraduate course. International Journal of Innovation in the Digital Economy (IJIDE). 2012;3(3):10-24.

[21] Santrock J.W. Educational psychology. New York: McGraw-Hill, 2017.

[22] Schunk DH. Learning theories an educational perspective. Boston, MA Pearson; 2015.

[23] Shirky C. Here comes everybody: The power of organizing without organizations: Penguin; 2008.

[24] Shraim KY. Pedagogical innovation within Facebook: A case study in tertiary education in Palestine. International Journal of Emerging Technologies in Learning (iJET). 2014;9(8):25-31.

[25] Stacey E. A constructivist framework for online collaborative learning: Adult learning and collaborative learning theory. Computer-supported collaborative learning in higher education. Hershey, PA: IGI Global; 2005.

[26] Taylor M. Leveraging social media for instructional goals: Status, possibilities, and concerns. New Directions for Teaching and Learning.2015;(144):37-46.in Stabile, C, and Ershler, J. eds. Constructivism Reconsidered in the Age of Social Media: New Directions for Teaching and Learning, Number 144. San Fracisco:Jossy Bass, 2015.

[27] Ventura R, Quero MJ. Using Facebook in university teaching: A practical case study. Procedia-Social and Behavioral Sciences. 2013;83:1032-8.

[28] Wankel LA, Blessinger P. New pathways in higher education: An introduction to using mobile technologies. Increasing student engagement and retention using mobile applications: Smartphones, Skype and texting technologies: Emerald Group Publishing Limited; 2013

[29] Wong K, Kwan R, Leung K, Wang FL. Exploring the potential benefits of Facebook on personal, social, academic and career development for higher education students. In International Conference on Hybrid Learning 2012 Aug 13 (pp. 253-264). Berlin, Heidelberg: Springer, 2012

[30] Zurweni W, Erwin TN, editors. Development of collaborative-creative learning model using virtual laboratory media for instrumental analytical chemistry lectures. American Institute of Physics Conference Series; 2017. 1868, (3) 
[31] Zygouris-Coe VI. Teaching discipline-specific literacies in grades 6-12: Preparing students for college, career, and workforce demands.New York,Ny:Routledge; 2014.

\section{AUTHOR PROFILES}

I am Jamridafrizal, wright know working with Department of Educational Technology, Postgraduate Program Universitas Negeri Jakarta, Jakarta,13220, Indonesia. My area of interest is higher education. For contact jamridafrizal@uinbanten.ac.id

My good name is Basuki Wibawa, my affiliation is Department of Educational Technology, Postgraduate Program Universitas Negeri Jakarta, Jakarta 13220, Indonesia. My area of interest is Technology. For any correspondence please contact me at: bwibawa@unj.ac.id

My good name is Nurdin Ibrahim, currently working with Department of Educational Technology, Postgraduate Program Universitas Negeri Jakarta, Jakarta 13220, Indonesia. My area of interest is social media and for further details contact me nurdin1349@yahoo.com. 